\title{
Investigation of the Phytoconstituents and Bioactivity of Various Parts of Wild Type and Cultivated Phyllanthus emblica L.
}

\author{
Ratna Mondal', Shakil Ahmed Polash1, Tanushree Saha², Zinia Islam¹, \\ Md. Maniruzzaman Sikder ${ }^{3}$, Nuhu Alam ${ }^{3}$, Md. Sharif Hossain ${ }^{1 *}$, Satya Ranjan Sarker ${ }^{{ }^{*}}$ \\ ${ }^{1}$ Department of Biotechnology and Genetic Engineering, Jahangirnagar University, Savar, Dhaka, Bangladesh \\ ${ }^{2}$ Department of Textile Engineering, Dhaka University of Engineering and Technology, Gazipur, Bangladesh \\ ${ }^{3}$ Department of Botany, Jahangirnagar University, Savar, Dhaka, Bangladesh \\ Email: *topuz79@yahoo.com, *satya.sarker@bgeju.edu.bd
}

How to cite this paper: Mondal, R., Polash, S.A., Saha, T., Islam, Z., Sikder, Md.M., Alam, N., Hossain, Md.S. and Sarker, S.R. (2017) Investigation of the Phytoconstituents and Bioactivity of Various Parts of Wild Type and Cultivated Phyllanthus emblica L.. Advances in Bioscience and Biotechnology, 8, 211-227.

https://doi.org/10.4236/abb.2017.87016

Received: May 31, 2017

Accepted: July 2, 2017

Published: July 5, 2017

Copyright $\odot 2017$ by authors and Scientific Research Publishing Inc. This work is licensed under the Creative Commons Attribution International License (CC BY 4.0).

http://creativecommons.org/licenses/by/4.0/ c) (i) Open Access

\begin{abstract}
Phyllanthus emblica L. belonging to the family Euphorbiaceae is a common medicinal plant in Bangladesh. In order to evaluate the phytoconstituents and bioactivity of various parts of $P$. emblica, both the wild type (i.e., small) and cultivated (i.e., big) fruits were collected from the local market of Bangladesh and six ethanolic extracts were prepared from various parts of the collected fruits for this current study. A comparative analysis of the phytochemical compositions and various bioactivities especially antibacterial, antifungal, and antioxidant activity of the six ethanolic extracts were accomplished. The qualitative phytochemical analysis of plant extracts revealed the presence of large amounts of proteins, carbohydrates, phenolic compounds, glycosides, alkaloids, coumarins, flavonoids, tannins, saponins and resins etc. The maximum antioxidant activity was observed for wild type $P$. emblica seed extracts and the minimum activity was observed for cultivated flesh extracts. Moreover, among the samples the wild type $P$. emblica extracts have excellent amount of total phenol contents and the highest free radical scavenging activity. It is also found that $P$. emblica samples were active against both gram-positive (i.e., $B$. subtilis) and gram-negative (i.e., E. coli, and $S$. typhi) bacteria. The highest antibacterial activity was achieved in the wild type $P$. emblica seed extracts against both pathogenic ( $S$. typhi) and non-pathogenic bacterial strains ( $E$. co$l i$, and B. subtilis). These samples showed almost no activity against Fusarium sp. fungus.
\end{abstract}

\section{Keywords}

Phyllanthus emblica, Total Phenol Content, Antioxidant Activity, Antimicrobial Activity, Zone of Inhibition, and Antifungal Activity 


\section{Introduction}

Infectious diseases are the leading cause of untimely death world-wide and it has become a global concern [1] [2] [3]. The clinical efficacy of many existing antibiotics is being threatened by rapid emergence of multidrug-resistant pathogens [4] [5]. Many infectious diseases have been known to be treated with herbal remedies throughout the history of mankind [6] [7]. Therefore, medicinal plants are important resources of new drugs. Natural products, either as pure compounds or as formulated with measured constituents of plant extracts, provide unlimited opportunities for the emergence of new drug leads [8]. There is a continuous and urgent need to discover new antimicrobial compounds with diverse chemical structures and novel mechanisms of action for new and re-emerging infectious diseases [1] [9]. Contrary to the synthetic drugs, antimicrobials of plant origin are not associated with many side effects [8] and have an enormous therapeutic potential to treat many infectious diseases.

Antioxidant refers to a compound that can delay or inhibit the oxidation of lipids or other molecules by inhibiting the initiation or propagation of reactive oxidative chain reactions and which can thus prevent or repair damage done to the body's cells by oxygen. It acts by several mechanisms, such as inhibition of scavenging activity against reactive oxygen species (ROS), reducing power, metal chelation, activity as antioxidative enzymes, and inhibition of oxidative enzymes. In recent years, there has been a considerable interest in finding natural antioxidants from plant materials. The antioxidant phytochemicals from plants, particularly flavonoids and other polyphenols have been reported to inhibit the propagation of free radical reactions to protect the human body from diseases. On the other hand, the use of synthetic antioxidants has been questioned because of their toxicity.

The fruit of Phyllanthus emblica commonly known as amla is highly valued as traditional medicine [10]. There are two varieties of $P$. emblica-cultivated (gramya) and wild (vanya). The wild type $P$. emblica is small, while cultivated $P$. emblica is big, smooth and juicy. Chemical composition of the $P$. emblica fruit contains more than $80 \%$ of water. It has proteins, carbohydrates, fiber and minerals and also contains gallic acid which is a potent polyphenol.

In Unani medicine, the dried fruits of $P$. emblica are used to treat hemorrhage, diarrhea and dysentery [11]. In addition, the fruit of $P$. emblica is diuretic, adaptogenic [12] and hepatoprotective [13] [14] [15] [16] [17]. The fruits are also reported to be anti-inflammatory [18], analgesic and antipyretic.

Several research works have been conducted on the leaves, fruits, and stems of Phyllanthus emblica. However no research work has been performed on the different parts of $P$. emblica fruits such as flesh, seed coat and seed. Furthermore, no research was also performed and compared the bioactivity of the wild type and cultivated $P$. emblica extracts. Therefore, the objective of the current research is to evaluate the potential antioxidant and antimicrobial activity of $P$. emblica fruit extracts on various microorganism to replace the synthetic drugs. The ultimate goal is to offer appropriate and efficient natural antioxidants and antimicrobial agents to the patients. 


\section{Materials and Methods}

\subsection{Chemicals and Reagents}

Absolute ethanol, methanol and Folin-Ciocalteu reagent were purchased from Merck, Germany. Gallic acid was purchased from Ashland Inc. USA. Ascorbic acid was bought from VEGA, China. 1-1-diphenyl-2-picryhydrazyl (DPPH) was collected from Sigma-Aldrich, USA. Agar powder was purchased from Titan Biotech Ltd., India. Peptone, yeast extract, sodium chloride and sodium carbonate were collected from UNI-CHEM, China.

Escherichia coli DH5a, Bacillus subtilis RBW, and Salmonella typhi were obtained from the department of Biotechnology and Genetic Engineering, Jahangirnagar University, Savar, Dhaka 1342, Bangladesh. The fungal strain Fusarium $s p$. was collected as pure culture from the Plant Pathology Laboratory, Department of Botany, Jahangirnagar University, Savar, Dhaka 1342, Bangladesh.

\subsection{Sample Collection and Preparation}

Phyllanthus emblica (amla) fruits were collected from the local market and were brought back to the laboratory for proper identification. Two types of $P$. emblica fruits were collected i.e., wild type and cultivated. Then they were washed thoroughly with distilled water for further processing.

The collected $P$. emblica fruits were cut into pieces separating the flesh and seed and then dried in hot air oven at $60^{\circ} \mathrm{C}$ for $5-8$ days to grind them properly. After drying, the seed coats were opened and then the seed and seed coats were separated. The dried parts (i.e., fruits, seed, and seed coat) of $P$. emblica were ground separately into fine powder. The powder was then stored in air tight container and kept in cool, dark and dry place for investigation.

\subsection{Preparation of Crude Extract and Fractionation}

About $5 \mathrm{~g}$ of powdered materials were taken in clean glass containers and soaked in $100 \mathrm{ml}$ of $70 \%$ ethanol and incubated $72 \mathrm{~h}$ in water bath shaker. Then the crude mixtures were filtrated using Whatman No.1 filter paper. The extracts were then concentrated by using a rotary evaporator at $60^{\circ} \mathrm{C}$ and stored in dry and cool place for further studies. Finally, $1 \%$ of the extract sample was prepared using $0.9 \% \mathrm{NaCl}$ solution.

\subsection{Test for Carbohydrates (Fehling's Test)}

Equal volume of Fehling's A (copper sulfate in distilled water) and Fehling's B (potassium tartarate and sodium hydroxide in distilled water) reagents were mixed and few drops of $P$. emblica extracts were added to the reagent mixture and boiled, where a brick red precipitate of cuprous oxide formed indicating the presence of reducing sugars.

\subsection{Test for Alkaloid (Wagner's Test)}

About $500 \mu \mathrm{l}$ of extracts was taken into the tubes. Then few drops of Wagner's 
reagent ( $1.27 \mathrm{~g}$ iodine $+2 \mathrm{~g} \mathrm{KI}_{2}$ in $100 \mathrm{ml}$ water) were added to the tubes. After that, the solution was heated at $60^{\circ} \mathrm{C}$ for 30 minutes. The presence of alkaloids gave reddish brown precipitate with Wagner's reagent.

\subsection{Test for Glycosides}

$1 \mathrm{ml}$ glacial acetic acid was added to $1 \mathrm{ml}$ of the extracts. Then few drops of $\mathrm{FeCl}_{3}$ were added to the extracts. The appearance of brown colored ring at the top indicated the presence of glycosides.

\subsection{Test for Tannins}

$1 \mathrm{ml}$ of distilled water was added to $0.5 \mathrm{ml}$ of the extracts and then $1-2$ drops of ferric chloride solution were added. Gallic tannin solution showed blue color, whereas catecholic tannin solution showed green black color.

\subsection{Test for Flavonoids (Alkaline Reagent Test)}

Few drops of sodium hydroxide solution were added to the test solution which initiated the formation of an intense yellow color and then turned colorless upon addition of few drops of diluted acid indicating the presence of flavonoids.

\subsection{Test for Saponins (Foam Test)}

$1 \mathrm{ml}$ of the extracts were added to $2 \mathrm{ml}$ of distilled water and then vortexed for few minutes. The formation of $1 \mathrm{~cm}$ thick layer of foam for 10 minutes indicated the presence of saponins.

\subsection{Test for Phenols (Ferric Chloride Test)}

$1 \mathrm{ml}$ of the extracts were dissolved in $1 \mathrm{ml}$ distilled water or ethanol, and then few drops of ferric chloride were added to the solution. The phenolic solution showed red, blue, green and purple color.

\subsection{Test for Amino Acids and Proteins (Xanthoprotic Test)}

$1 \mathrm{ml}$ of the extracts were added to $2-6$ drops of concentrated $\mathrm{HNO}_{3}$. The solution was then neutralized using concentrated sodium hydroxide solution. The presence of protein and amino acid in the extract solution showed yellow or orange color.

\subsection{Test for Coumarins}

To confirm the presence of coumarins, $3 \mathrm{ml}$ of $10 \% \mathrm{NaOH}$ and $2 \mathrm{ml}$ of the extracts were mixed in different tubes. The presence of yellow color indicated the presence of coumarins in the $P$. emblica extracts.

\subsection{Test for Resins}

Ethanolic extracts of $P$. emblica were mixed with few drops of acetic anhydride followed by the addition of $1 \mathrm{ml}$ concentrated sulfuric acid. The presence of yellow to orange color confirmed the presence of resins in the extract samples. 


\subsection{Determination of Total Phenol Content}

The content of total phenolic compounds in the ethanolic extracts of $P$. emblica was determined by Folin-Ciocalteu Reagent (FCR). At first, all the reagents such as sodium carbonate $(7.5 \%)$, sodium chloride solution (0.9\%), Folin-ciocalteu $(10 \% \mathrm{v} / \mathrm{v})$, and different $P$. emblica ethanolic extracts were prepared. Gallic acid was used as standard and a solution of $500 \mu \mathrm{g} / \mathrm{ml}$ was prepared as stock. P. emblica extracts or standard solutions (100 $\mu \mathrm{l})$ of different concentration were taken into test tubes. Then $500 \mu \mathrm{l}$ of Folin-ciocalteu (diluted 10 fold) reagent was added to all the test tubes. Finally, $400 \mu \mathrm{l}$ of sodium carbonate was added to the test tubes and incubated for 60 minutes at room temperature to complete the reaction. The absorbance of the solutions was then measured at $765 \mathrm{~nm}$ using a UV-visible spectrophotometer (Optizen POP, Korea) against blank containing methanol. Different concentrations of gallic acid were used to prepare a standard curve to determine the total phenol content (TPC) value of the extracts. The TPC of the ethanolic extracts of $P$. emblica was expressed as gallic acid equivalent per milliliter ( $\mu \mathrm{g} \mathrm{GAE} / \mathrm{ml})$.

\subsection{Determination of Antioxidant Activity (DPPH Free Radical Scavenging Assay)}

The ability of the ethanolic extracts of $P$. emblica to scavenge DPPH free radicals was determined according to the method described by Manzocco et al., 1998 with little modification [19]. Briefly, sample extracts (stock: $1.0 \mathrm{mg} / \mathrm{ml}$ ) were diluted to two different concentrations such as 50 and $100 \mu \mathrm{g} / \mathrm{ml}$. Both the diluted sample extracts $(730 \mu \mathrm{l})$ and different concentrations of standard (i.e., freshly prepared ascorbic acid) solution were taken into different test tubes. $20 \mu \mathrm{HCl}$ $(1.0 \mathrm{M})$ was added to all the test tubes containing either the ethanolic sample extracts or ascorbic acid. Then methanolic solution of DPPH $(250 \mu \mathrm{l}, 0.004 \%)$ was added to all the test tubes and incubated for 30 minutes in the dark and cold environment. After 30 minutes incubation, the absorbance of all the solutions was measured at $517 \mathrm{~nm}$ using a UV-visible spectrophotometer (Optizen POP, Korea) against a blank containing methanol.

The percentage (\%) of free radical scavenging activity was calculated from:

$$
(\mathrm{Ab}-\mathrm{As}) / \mathrm{Ab} \times 100
$$

Here, $\mathrm{Ab}$ is the absorbance of the blank, and As is the absorbance of the standard or extract sample. The percentage (\%) of free radical scavenging activity was plotted against the concentration of the plant extracts and the value of $\mathrm{IC}_{50}$ (i.e., the concentration of the plant extract required to inhibit the formation of free radicals by $50 \%$ ) was calculated from the regression line obtained. Tests were carried out in triplicate and the average value was taken.

\subsection{Antibacterial Activity Determination}

\subsubsection{Preparation of Culture Inoculums for Test}

Both gram-positive (i.e., Bacillus subtilis) and gram-negative (i.e., Escherichia coli, and Salmonella typhi) bacteria were taken for the study. In an aseptic con- 
dition under laminar air flow, the test organisms were transferred from the glycerol stocks to the nutrient broth with the help of a transfer loop to get fresh pure cultures. The inoculated strains were then incubated for 24 hours at $37^{\circ} \mathrm{C}$ for their optimum growth. These fresh cultures were then used for the investigation of the antimicrobial activity of the ethanolic extracts of $P$. emblica.

\subsubsection{Preparation of the Test Plates}

The overnight grown bacterial cultures $(100 \mu \mathrm{l})$ were transferred to sterile agar plates in an aseptic condition and spreaded uniformly using a glass spreader. The plates were then incubated at $37^{\circ} \mathrm{C}$ for $\sim 24 \mathrm{~h}$.

\subsubsection{Preparation of Discs}

Sterile metrical filter paper discs (Oxoid, UK) were taken in a blank petri plate. Herein, three types of discs were used for the antibacterial screening such as standard discs (positive control: chloramphenicol), blank discs (negative control), and sample discs (discs containing sample extracts). For the preparation of sample discs, blank discs were soaked with different concentration of the sample extracts (i.e., $25 \mu \mathrm{g} / \mu \mathrm{l}$, and $50 \mu \mathrm{g} / \mu \mathrm{l}$ ). Furthermore, blank discs were soaked with chloramphenicol to prepare the standard discs. Finally, all the discs were dried properly at room temperature.

\subsubsection{Determination of Antibacterial Activity by Disc Diffusion Method} Antibacterial activity of $P$. emblica extracts were investigated by disc diffusion method. Briefly, LB agar medium was used to grow bacteria. Dried and sterile metrical filter paper discs (6 $\mathrm{mm}$ diameter) containing $P$. emblica extracts of known concentrations were placed on nutrient agar medium uniformly seeded with the test microorganisms. The plates were then incubated at $37^{\circ} \mathrm{C}$ for 24 hours for optimum growth of the microorganisms.

\subsubsection{Determination of the Zone of Inhibition}

The antibacterial activity of $P$. emblica extracts were determined by their ability to prevent the growth of microorganisms surrounding the discs which gives a clear zone of inhibition. After incubation, the antibacterial activities of the test materials were determined by measuring the diameter of the zone of inhibition in millimeter with a transparent scale.

\subsection{Determination of $\mathrm{IC}_{50}$ (Inhibitory Concentration 50) Value}

Broth dilution method is one of the most frequently used methods to determine $\mathrm{IC}_{50}$ value of tested samples. The $\mathrm{IC}_{50}$ values of all the ethanolic extracts of $P$. emblica were determined through serial dilution method as described by Polash et al. [20]. Briefly, different concentration of the extracts (i.e., 5, 10, 20, 40, 80 and $160 \mu \mathrm{g} / \mathrm{ml}$ ) were added to the bacterial cultures and the final volume was made up to $2.0 \mathrm{ml}$ before incubating overnight at $37^{\circ} \mathrm{C}$ upon gentle shaking. For each batch of $\mathrm{IC}_{50}$ determinations, a blank tube (i.e., $2 \mathrm{ml} \mathrm{LB}$ broth without any bacterial strains) and a positive control (10 $\mu \mathrm{g}$ of chloramphenicol antibiotic was added to bacterial cultures) were included. The absorbance of all the tubes was 
taken at $600 \mathrm{~nm}$ using a UV-visible Spectrophotometer (Optizen POP, Korea). The experiment was performed multiple times and the data expressed as a mean of several replications $(n=3)$ and standard deviations.

The data were plotted into the graph and the $\mathrm{IC}_{50}$ values were found from the following equation:

$$
Y=a x+b
$$

Here, $Y=50 \%, x=$ concentration of the extract in which $50 \%$ inhibition occurs, $b=$ constant, $a=$ coefficient.

\subsection{Antifungal Activity Test (Poisoned Food Method)}

Poisoned food method is mostly used to evaluate the antifungal activity against molds. Richard medium was used to prepare the test plates to grow Fusarium sp. The antifungal agent or the ethanolic extracts of $P$. emblica were incorporated into the molten agar at a desired concentration and mixed properly. The medium was then poured into petridishes. After overnight pre incubation, the inoculation was done by a mycelia disc of the tested fungi ranging from 2 to $5 \mathrm{~mm}$, which was deposited in the center of the plate. After further incubation under suitable conditions for the fungal strain tested, the diameters of fungal growth in control and treated plates were measured.

\section{Results}

\subsection{Phytochemical Screening}

The qualitative chemical assay of the crude ethanolic extract of different $P$. emblica samples has been presented in Table 1 . Almost all the P. emblica samples showed strong and positive results for Fehling's test indicating the presence of carbohydrate. In case of alkaloid test, all of the samples showed very strong response to Wagner's reagent revealing the presence of a significant amount of alkaloid in the sample extracts. Poor presence of saponin was observed in the

Table 1. Phytochemical screening of the ethanolic extracts of wild type and cultivated Phyllanthus emblica.

\begin{tabular}{ccccccc}
\hline & CF & CSC & CS & WF & WSC & WS \\
\hline Saponin & ++ & - & + & - & - & - \\
Tannin & +++ & +++ & +++ & +++ & +++ & +++ \\
Reducing sugar & +++ & + & ++ & +++ & ++ & +++ \\
Glycoside & +++ & + & ++ & +++ & +++ & + \\
Phenol & +++ & +++ & +++ & +++ & +++ & +++ \\
Alkaloid & - & +++ & +++ & - & ++ & + \\
Coumarin & - & ++ & + & - & + & ++ \\
Flavonoid & ++ & +++ & +++ & ++ & +++ & +++ \\
Protein & +++ & ++ & ++ & + & +++ & - \\
Resin & +++ & - & - & +++ & - & ++ \\
\hline
\end{tabular}

N.B: $+++=$ Strong; $++=$ Moderate; $+=$ Weak; $-=$ Negative; WF $=$ Wild type flesh, WSC $=$ Wild type seed coat, WS = Wild type seed, $\mathrm{CF}=$ Cultivated flesh, $\mathrm{CSC}=$ Cultivated seed coat, and CS = Cultivated seed. 
ethanolic extracts of cultivated $P$. emblica flesh and seed and the rest of the samples showed negative response to the saponin test.

All the ethanolic extracts of $P$. emblica showed very strong positive response in the test for tannin. Positive responses to $\mathrm{FeCl}_{3}$ test for glycoside indicated the presence of phenolic glycosides in the samples. Test of phenol also gave the strong positive response for all of the ethanolic extracts of both the wild type and cultivated $P$. emblica. Cultivated seed coat and seed of $P$. emblica and its wild type seed coat and seed showed the positive response to the coumarin test. On the other hand, the extracts of both the cultivated $P$. emblica flesh and its wild type flesh showed no response to the coumarin test. Alkaline reagent test was performed to detect the presence of flavonoids in the sample extracts and all the extracts showed positive response to the flavonoid test. Furthermore, almost all the sample extracts except the wild type seed showed positive response to xanthoprotic test. In case of test for resins, the ethanolic extracts of only cultivated flesh, wild type flesh and seed showed positive results.

\subsection{Determination of Total Phenol Content}

The total phenol content (TPC) has been expressed as $\mu \mathrm{g}$ GAE/ml (Gallic acid equivalent). The data revealed that all the $P$. emblica extracts showed significant amount of total phenol content in a dose dependent manner as presented in Figure 1. Among the $P$. emblica samples, wild type seed extract at a concentration of $100 \mu \mathrm{g} / \mathrm{ml}$ showed the highest amount of phenolic content (i.e., 42.47 $\mu \mathrm{g} / \mathrm{ml})$ followed by the cultivated seed coat extract $(39.51 \mu \mathrm{g} / \mathrm{ml})$. On the other hand, the cultivated seed extract at a concentration of $50 \mu \mathrm{g} / \mathrm{ml}$ showed the lowest amount of phenolic content $(22.56 \mu \mathrm{g} / \mathrm{ml})$.

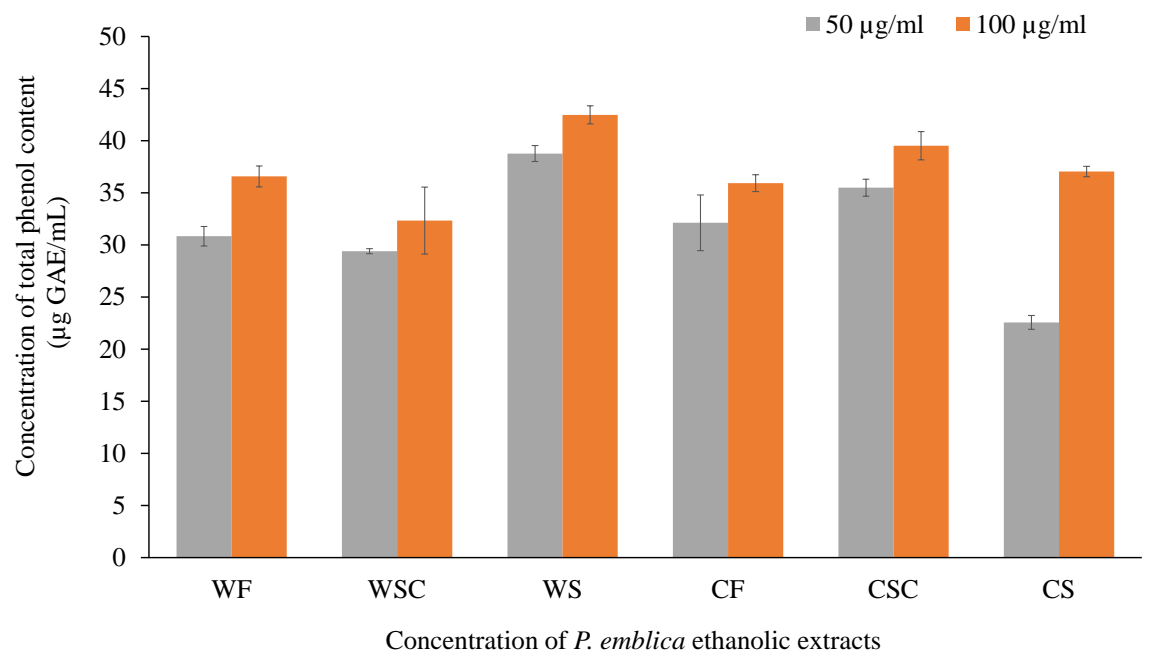

Figure 1. Comparison of total phenol content (TPC) among different $P$. emblica extracts. Gray colored bar indicates the TPC of different $P$. emblica ethanolic extracts in $50 \mu \mathrm{g} / \mathrm{ml}$ concentration and orange colored bar indicates the TPC of different $P$. emblica ethanolic extracts in $100 \mu \mathrm{g} / \mathrm{ml}$ concentration. Data represents mean value $\pm \mathrm{SD}(\mathrm{n}=4)$. Six different samples were taken, $\mathrm{WF}=$ Wild type flesh, $\mathrm{WSC}=$ Wild type seed coat, $\mathrm{WS}=$ Wild type seed, $\mathrm{CF}=$ Cultivated flesh, $\mathrm{CSC}=$ Cultivated seed coat, and CS $=$ Cultivated seed. 


\subsection{Antioxidant Activity Assay}

Freshly prepared DPPH is purple in color by itself and gives the maximum absorbance at $517 \mathrm{~nm}$. However, this purple color disappears when an antioxidant is mixed with the DPPH solution. In the present study, the antioxidant activity of the ethanolic extracts of flesh, seed coat, and seed of the wild type and cultivated $P$. emblica was investigated using the DPPH scavenging assay. The ethanolic extracts of cultivated seed coat and wild type seed showed the highest free radical scavenging activity as shown in Figure 2(a). The other ethanolic extracts of $P$. emblica demonstrated moderate free radical scavenging activity with diminutive antioxidant activity at lower concentration and high antioxidant activity at higher concentration.

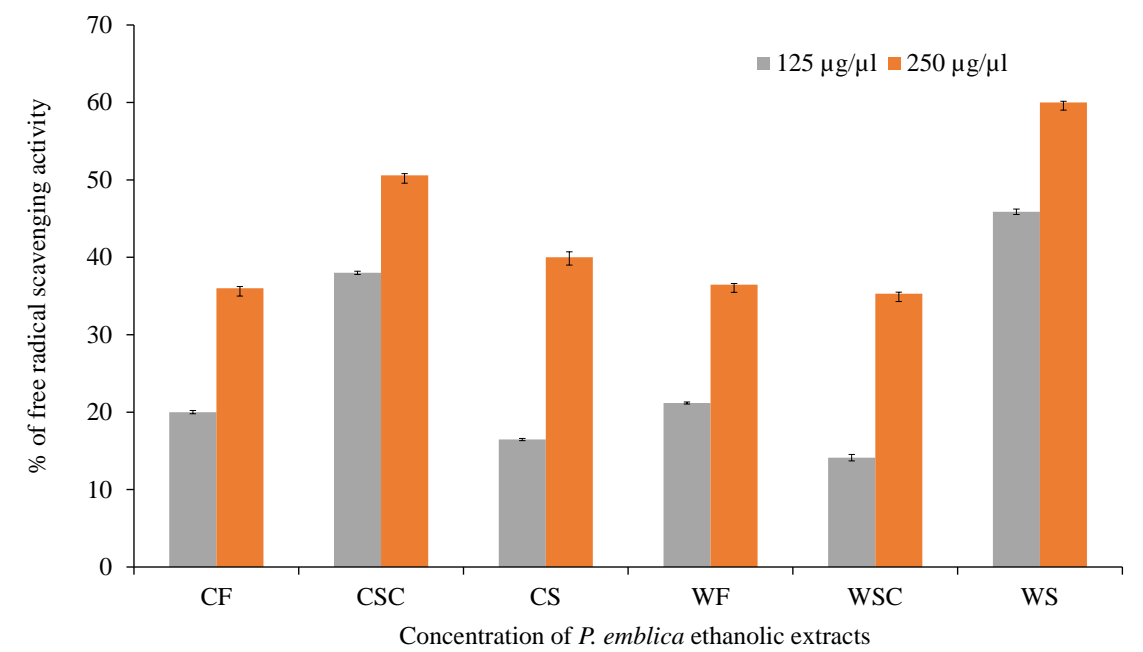

(a)

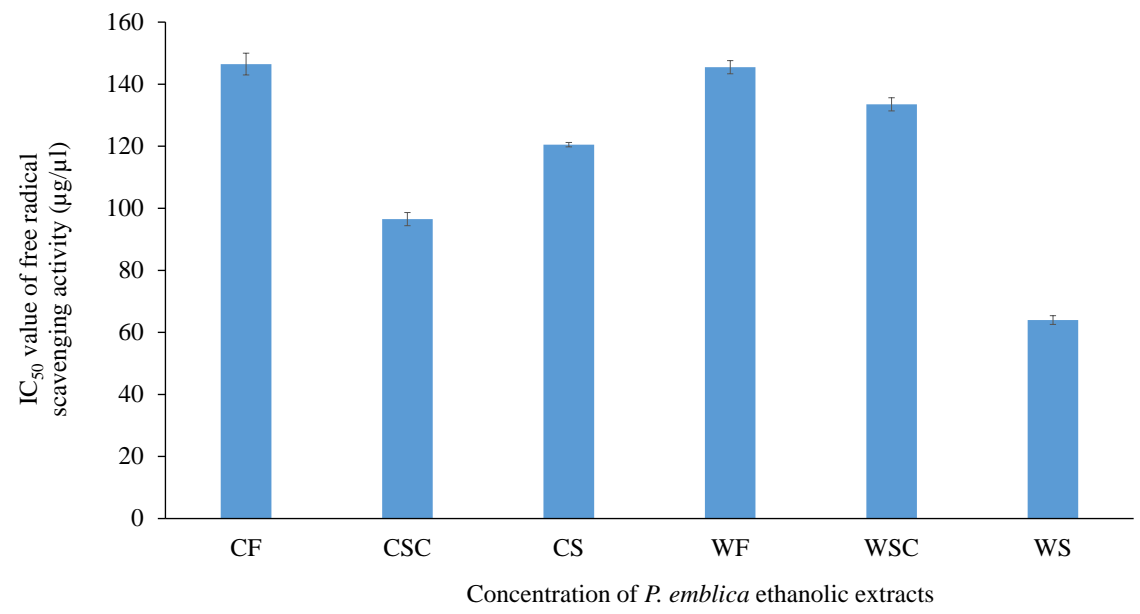

(b)

Figure 2. Free radical scavenging activity (\%) of the ethanolic extracts of $P$. emblica. Two different concentrations of $P$. emblica extracts (i.e., $125 \mu \mathrm{g} / \mu \mathrm{l}$ and $250 \mu \mathrm{g} / \mu \mathrm{l}$ ) were used. The free radical scavenging activity (\%) increased as the concentration of the sample extracts increased. (a) showed the free radical scavenging activity of individual sample; and (b) showed the comparison of $\mathrm{IC}_{50}$ value of different sample extracts. Six different samples were taken, $\mathrm{WF}=$ Wild type flesh, $\mathrm{WSC}=$ Wild type seed coat, $\mathrm{WS}=$ Wild type seed, $\mathrm{CF}=$ Cultivated flesh, $\mathrm{CSC}=$ Cultivated seed coat, and CS $=$ Cultivated seed. 
To determine the $\mathrm{IC}_{50}$ value of the ethanolic extracts of $P$. emblica to scavenge DPPH free radical activity, the absorbance of different test solutions with different concentrations of $P$. emblica samples were plotted and a line was found for each of the $P$. emblica sample. The calculated $\mathrm{IC}_{50}$ value of different $P$. emblica extracts to scavenge DPPH free radical activity is presented in Figure 2(b). The $\mathrm{IC}_{50}$ value of cultivated flesh, seed coat, and seed extracts were $144 \mu \mathrm{g} / \mu \mathrm{l}, 98$ $\mu \mathrm{g} / \mu \mathrm{l}$, and $121 \mu \mathrm{g} / \mu \mathrm{l}$, respectively. Furthermore, the $\mathrm{IC}_{50}$ value of wild type flesh, seed coat, and seed extracts were $144 \mu \mathrm{g} / \mu \mathrm{l}, 135 \mu \mathrm{g} / \mu \mathrm{l}$, and $65 \mu \mathrm{g} / \mu \mathrm{l}$, respectively. The lowest $\mathrm{IC}_{50}$ value was $65 \mu \mathrm{g} / \mu \mathrm{l}$ of wild type seed extract and the highest $\mathrm{IC}_{50}$ value was $144 \mu \mathrm{g} / \mu \mathrm{l}$ of both the cultivated flesh and wild type flesh extracts.

\subsection{Antibacterial Activity Assay}

The antibacterial activity of the ethanolic extracts of $P$. emblica resulted in the formation of the zone of inhibition in the plates of different gram-positive ( $B$. subtilis) and gram-negative (E. coli and $S$. typhi) bacteria. Antibacterial activity was measured by determining the diameter of the zone of inhibition in millimeter as shown in Figures 3(a)-(c).

These data revealed that almost all the ethanolic extracts of $P$. emblica have antibacterial activity against both gram-positive and gram-negative bacteria and the activity is concentration dependent. The maximum activity was observed for wild type seed extract against both gram-positive and gram-negative bacteria. Chloramphenicol and saline were used as positive and negative control, respectively. Chloramphenicol showed the highest zone of inhibition and saline showed no zone of inhibition.

\subsection{Determination of $\mathrm{IC}_{50}$ Value}

The $\mathrm{IC}_{50}$ value explains the bacteriostatic as well as the bactericidal activity of the $P$. emblica extracts which is required to inhibit the bacterial growth and multiplication by $50 \%$. It is well known that the absorbance of bacterial culture increases with the increased concentration of bacteria. Since the extracts have both the bacteriostatic and bactericidal activity, the absorbance of bacterial culture was reduced as the concentration of $P$. emblica extracts were increased and the ethanolic extract of wild type seed coat showed the lowest $\mathrm{IC}_{50}$ value among all the extracts (Figures $4(\mathrm{a})-(\mathrm{c})$ ).

\subsection{Antifungal Activity}

In order to evaluate the antifungal activity, ethanolic extracts of flesh, seed coat, and seed for both wild type and cultivated $P$. emblica samples were used. Antifungal activity of $P$. emblica extracts was screened using the poisoned food method. No inhibition was observed for discs loaded with the saline (negative control). Similarly, ethanolic extract of wild type $P$. emblica seeds showed approximately no inhibitory activity against Fusarium sp. However, clotrimazole discs (positive control) showed strong inhibition. 


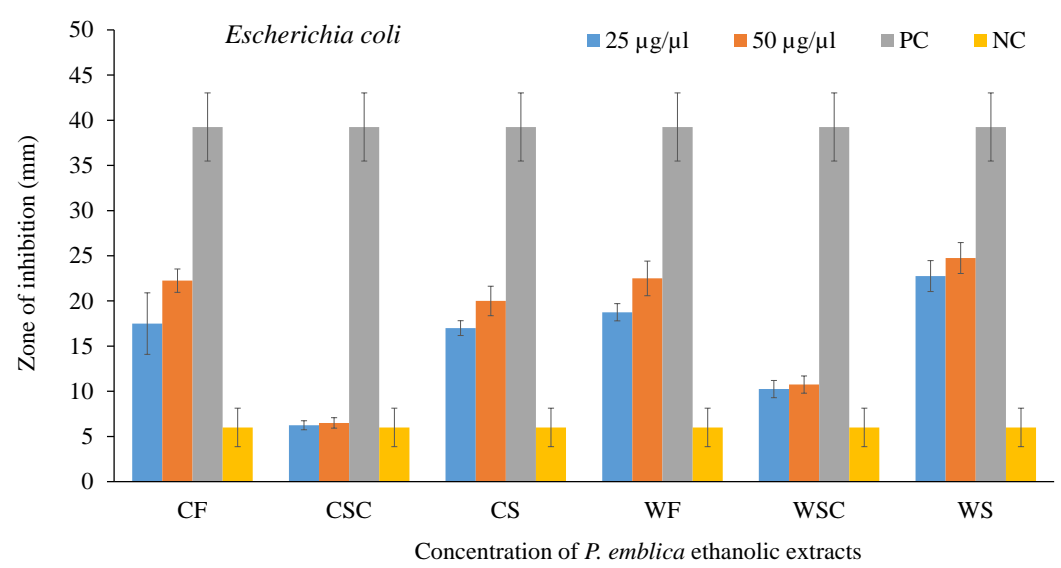

(a)

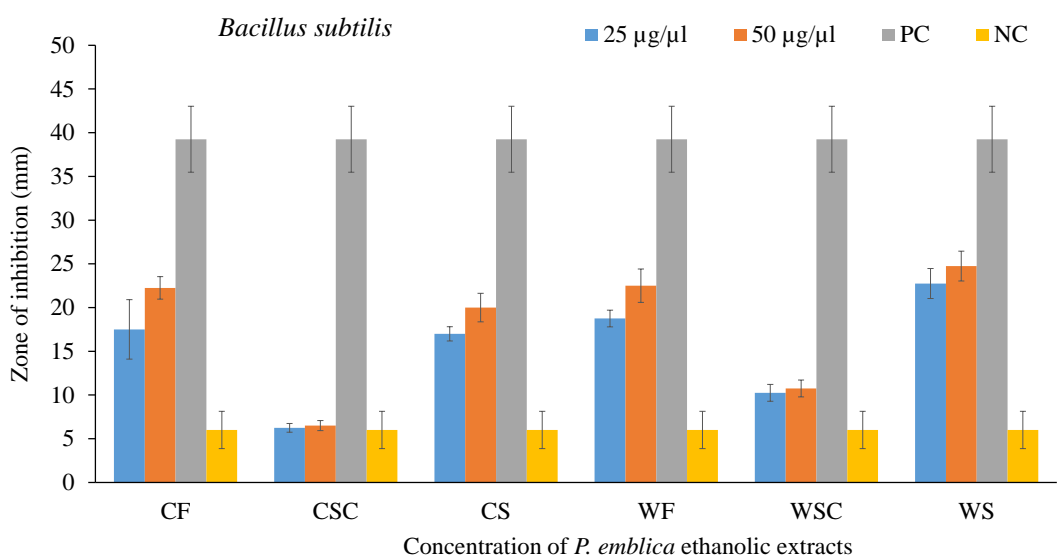

(b)

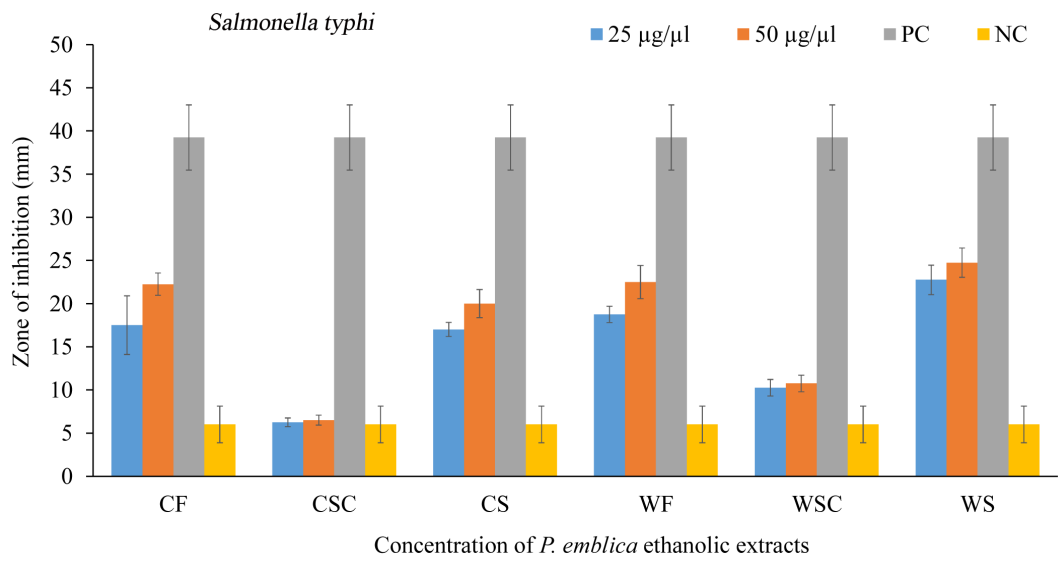

(c)

Figure 3. Antibacterial activity assay of the ethanolic extracts of $P$. emblica. Effects of different extracts on (a) E. coli; (b) B. subtilis, and (c) S. typhi were investigated. The graph shows the zone of inhibition (in mm) of different extracts in $25 \mu \mathrm{g} / \mathrm{ml}$ and $50 \mu \mathrm{g} / \mathrm{ml}$ concentrations, and the chloramphenicol as positive control (PC) and saline $(0.9 \% \mathrm{NaCl})$ as negative control (NC) against the mentioned bacterial strains. The $\mathrm{X}$-axis represents the different extract samples and the $\mathrm{Y}$-axis represents the zone of inhibition (in $\mathrm{mm}$ ) against all the bacteria. The data represented as an average value of four different replications \pm standard deviations $(\mathrm{SD})$. Six different samples were taken, WF $=$ Wild type flesh, WSC = Wild type seed coat, WS = Wild type seed, CF = Cultivated flesh, CSC = Cultivated seed coat, and CS = Cultivated seed. 


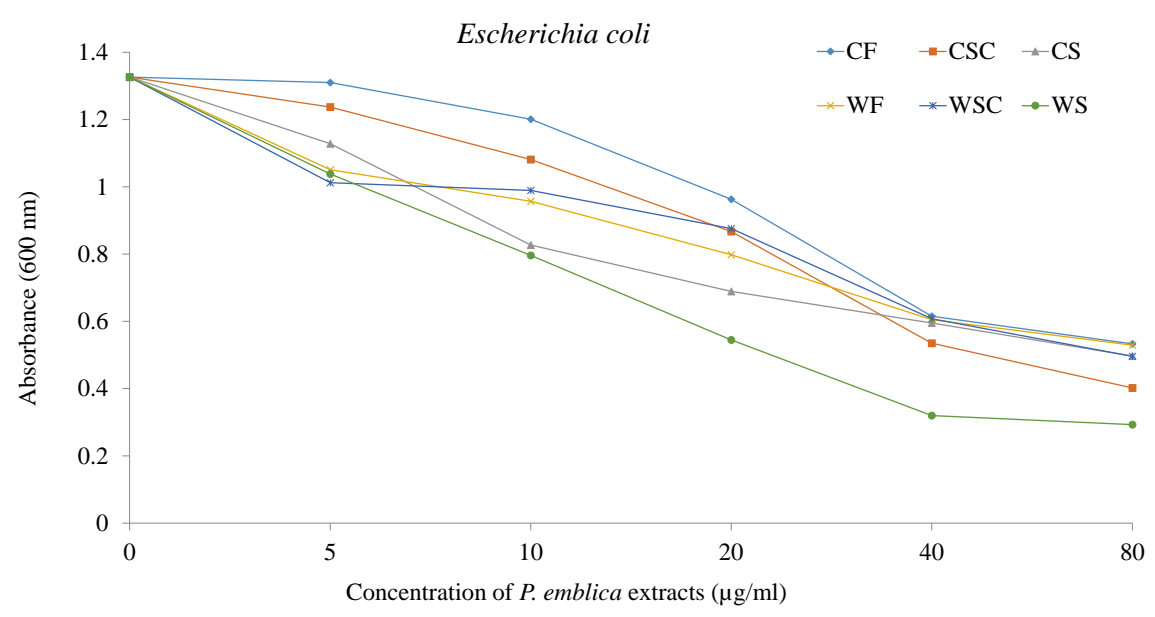

(a)

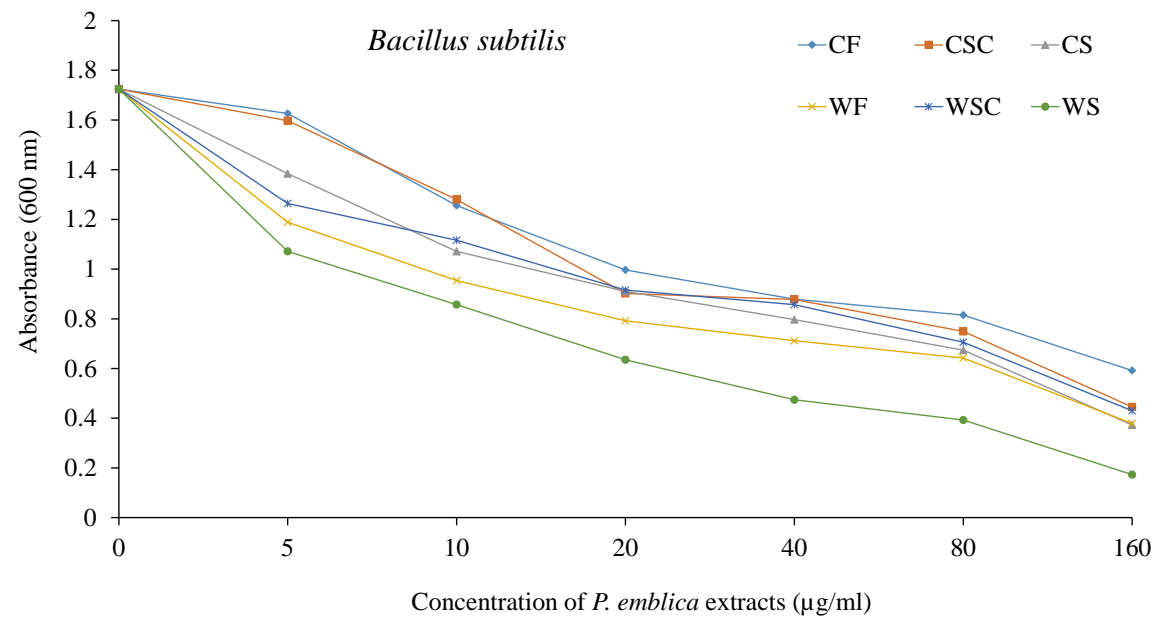

(b)

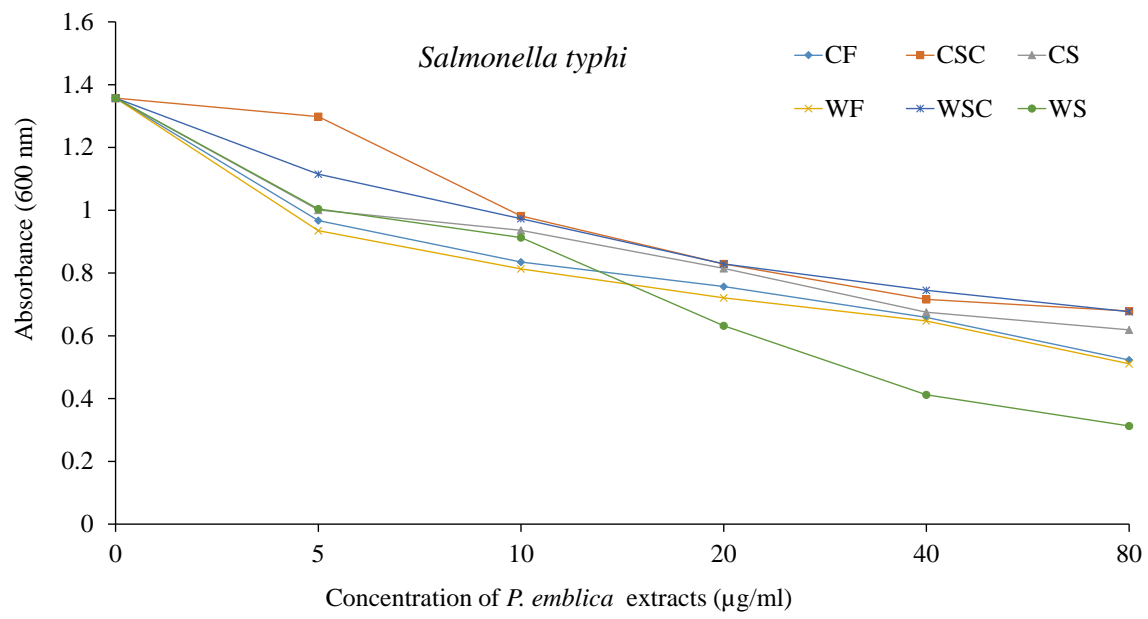

(c)

Figure 4. Determination of $\mathrm{IC}_{50}(\mu \mathrm{g} / \mathrm{ml})$ value of different $P$. emblica extracts against (a) E. coli; (b) B. subtilis, and (c) S. typhi. However, the absorbance value decreased with the increased amount of sample extracts. All the values are mean \pm SD of three determinations. Six different samples were taken, WF $=$ Wild type flesh, WSC $=$ Wild type seed coat, $\mathrm{WS}=$ Wild type seed, $\mathrm{CF}=$ Cultivated flesh, $\mathrm{CSC}=$ Cultivated seed coat, and CS = Cultivated seed. 
The antifungal activity of different $P$. emblica extracts against Fusarium sp. was presented in Figure 5. The positive control showed maximum zone of inhibition which was about $1.6 \mathrm{~cm}$ against Fusarium sp. at a concentration of 5 $\mu \mathrm{g} / \mathrm{ml}$ concentration. The negative control (saline) showed $3.27 \mathrm{~cm}$ of inhibition zone against Fusarium sp.

\section{Discussion}

The present study was carried out to make a comparative profile on the phenolic content and bioactivity of three parts (i.e., flesh, seed coat, and seed) of two $P$. emblica samples (i.e., wild type and cultivated) collected from the local market of Savar, Dhaka, Bangladesh.

The phytochemical analysis of the fruit part of both the wild type and cultivated $P$. emblica samples showed the presence of saponin, tannin, carbohydrate, glycoside, phenol, alkaloid, flavonoid, coumarin, protein and resin in large amount. According to the previous study, the presence of phytochemicals may account for their various pharmacological activities. The present findings indicated that the different types and parts of $P$. emblica contain different amounts of phytochemicals.

Polyphenols associated with fruits and vegetables are the largest group of phytochemicals that have been gaining acceptance because of having health benefits. According to Deepaa et al., plant polyphenols have drawn increasing attention due to their potent antioxidant properties and their marked effects in the prevention of various oxidative stress associated diseases such as cancer [21]. In the current study, all the $P$. emblica extracts have excellent amount of total phenol contents (Table 1). The maximum amount of total phenol contents was observed in the wild type seed extracts and the minimum amount was observed in

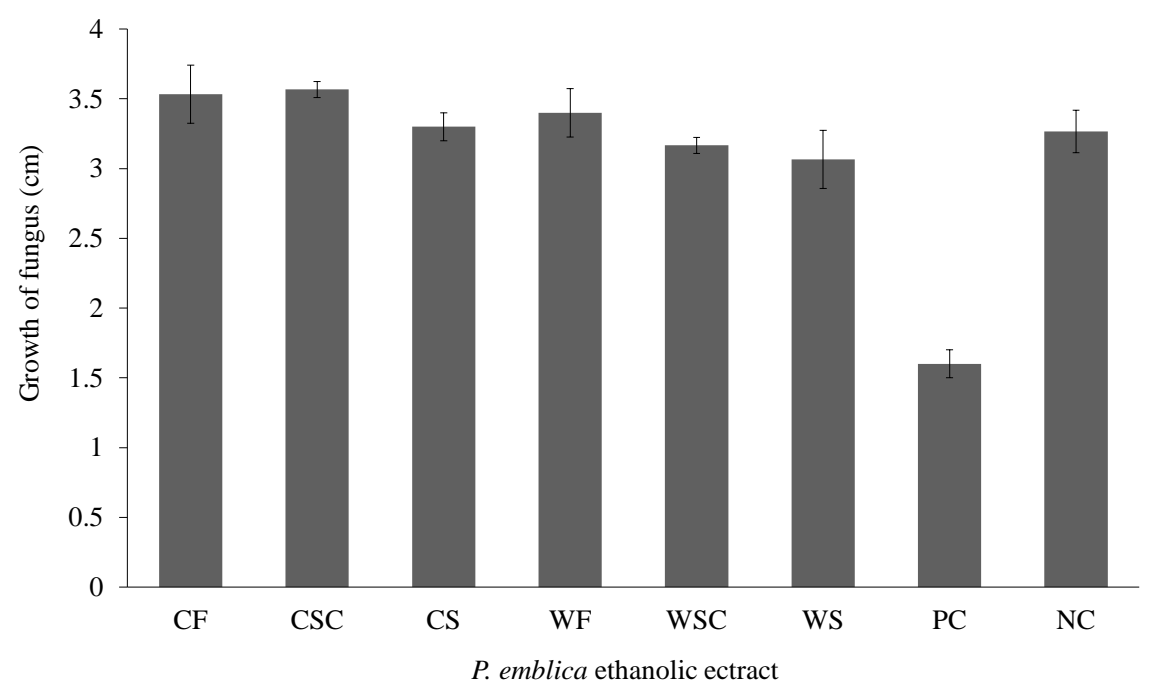

Figure 5. Growth of Fusarium sp. in different $P$. emblica samples. Six different samples were taken, WF = Wild type flesh, WSC = Wild type seed coat, WS = Wild type seed, CF $=$ Cultivated flesh, $\mathrm{CSC}=$ Cultivated seed coat, and CS $=$ Cultivated seed. $\mathrm{PC}=$ Positive control (Clotrimazole), $\mathrm{NC}=$ Negative control (saline solution). 
cultivated seed extracts. Therefore, our study suggests that the ethanolic extracts of $P$. emblica could be a potential source of natural antioxidants.

Free radicals are defined as molecules or ions containing an unpaired electron in its outer orbital that makes them very reactive toward various other molecules. If free radicals and other reactive oxygen species (ROS) are not removed or neutralized, it can target cellular constituents like lipid membranes, protein, DNA and RNA. Due to the adverse effects of synthetic antioxidants, researchers have channeled their interest in isolating natural antioxidants which are very effective to control the oxidative stress and hence prevent the initiation of disease propagation. In the present study, the highest DPPH free radical scavenging activity was performed by the ethanolic seed extract of wild type $P$. emblica and the lowest scavenging activity was performed by the ethanolic flesh extract of both the wild type and cultivated $P$. emblica. So the $\mathrm{IC}_{50}$ value for DPPH free radical scavenging activity is minimum for wild type seed extract and maximum in case of both the wild type and cultivated flesh extracts. The antioxidant property increased with the increased concentration of $P$. emblica extracts. The $P$. emblica ethanolic extract showed antioxidant activity even at a very low concentration (i.e., $125 \mu \mathrm{g} / \mathrm{ml}$ ). The reducing ability of the ethanolic extracts of $P$. emblica were compared with ascorbic acid which was taken as standard. Our data showed that all six ethanolic extracts of $P$. emblica have considerable free radical scavenging activity and wild type seed extract was the best among them. The free radical scavenging activity is due to the presence of a significant amount of phenolic compounds especially flavonoids (Table 1) which brings about the chelation of the free radicals [22]. Other phenolic compounds were also very good free radical scavengers because of the presence of hydroxyl groups [23].

Naturally occurring substances of plant origin have been reported to inhibit the growth of microorganisms. Plants extracts are being used in folk and even modern medical practices for the treatment of different ailments, most of which are due to microbial infections [24]. The development of resistance to antibiotics is an almost inevitable consequence of their application [25]. The rate of antibiotic resistance development depends on the respective group of antibiotics and their products. The use of plant extracts or phytochemicals with known antimicrobial properties can be of great importance for therapeutic purposes. Our data suggest that the plants which have been found to have antimicrobial properties in vitro also have in vivo antimicrobial activity and contains a wide variety of secondary metabolites, such as tannins, terpenoids, alkaloids and flavonoids. In this study, the antibacterial property of the ethanolic extracts of both the wild type and cultivated $P$. emblica have been investigated against a gram-negative (i.e., B. subtilis) and two gram-negative (i.e., E. coli and S. typhi) bacterial strains. The ethanolic extracts of $P$. emblica showed antibacterial activity against both the gram-positive and gram-negative bacteria (Figures 3(a)-(c)). Our data indicated that inhibitory action of different extracts is dependent on their concentrations. The higher the concentration, the greater the inhibitory action of the plant extracts to the test organisms. The results support the application of $P$. 
emblica extracts as traditional medicine and suggest that the extracts possess secondary metabolites with excellent antibacterial properties that can be used as antimicrobial agents for new drug discovery. Therefore, this study has revealed the importance of natural products to control antibiotic resistant bacteria which are a threat to human health and can serve as an important platform for the development of inexpensive, safe and effective medicines. In another experiment, we found that none of the $P$. emblica extracts showed any inhibition on the growth of Fusarium sp. fungus.

\section{Conclusion}

A comparative study of phytochemicals and bioactivity has been carried out among six $P$. emblica samples. The results obtained from this work revealed that the contained bioactive agents are responsible for the antimicrobial properties in different parts of $P$. emblica fruits. The present work also reveals that different parts of $P$. emblica possess good antioxidant potential presumably because of its phytochemical constituents. Finding of phytochemicals and other bioactivity in the dose dependent manner can be subjected to further study. The plant can be further screened against various diseases in order to find out its unexplored efficacy and can be a potential source of chemically interesting and biologically important drug candidates. Based on the result of this study it can be said that $P$. emblica fruit is an effective antimicrobial and antioxidant agent that can be used for folk medicine and will be a good source to treat and control many diseases. These findings could also be of commercial interest to both pharmaceutical companies and research institutes for the discovery of new drugs.

\section{Acknowledgements}

This research was supported by Jahangirnagar University Research Grants 201415, Savar, Dhaka 1342, Bangladesh, and University Grants Commission Research Grants 2015-16, Govt. of Bangladesh.

\section{Conflict of Interest}

The authors declare no conflict of interest whatsoever.

\section{References}

[1] Kumar, A., Singh, A. and Dora, J. (2012) Essentials Perspectives for Emblica officinalis. International Journal of Pharmaceutical and Chemical Sciences, 1, 11-18.

[2] Mahady, G.B. (2005) Medicinal Plants for the Prevention and Treatment of Bacterial Infections. Current Pharmaceutical Design, 11, 2405-2427. https://doi.org/10.2174/1381612054367481

[3] Sakata, H., Toyonagam, Y., Sato, Y., Hanaki, H., Nonoyama, M., Oishi, T. and Sunakawa, K. (2009) Nationwide Survey of the Development of Drug-Resistance in the Pediatric Field: Drug Sensitivity of Haemophilus influenzae in Japan. Journal of Infection and Chemotherapy, 15, 402-409. https://doi.org/10.1007/s10156-009-0729-1

[4] Penner, R., Fedorak, R.N. and Madsen, K.L. (2005) Probiotics and Nutraceuticals: 
Non-Medicinal Treatments of Gastrointestinal Diseases. Current Opinion in Pharmacology, 5, 596-603. https://doi.org/10.1016/j.coph.2005.06.009

[5] Westh, H., Zinn, C.S. and Rosdahl, V.T., Sarisa Study Group (2004) An International Multicenter Study of Antimicrobial Consumption and Resistance in Staphylococcus aureus Isolates from 15 Hospitals in 14 Countries. Microbial Drug Resistance, 10, 169-176. https://doi.org/10.1089/1076629041310019

[6] Wadud, A., Prasad, P.V., Rao, M.M. and Narayana, A. (2006) Evolution of Drug: A Historical Perspective. Bulletin of the Indian Institute of History of Medicine ( $\mathrm{Hy}$ derabad), 37, 69-80.

[7] Mitscher, L.A., Drake, S., Gollapudi, S.R. and Okwute, S.K. (1987) A Modern Look at Folkloric Use of Anti-Infective Agents. Journal of Natural Products, 50, 1025 1040. https://doi.org/10.1021/np50054a003

[8] Mukherjee, P.K. and Wahile, A. (2006) Integrated Approaches towards Drug Development from Ayurveda and Other Indian System of Medicines. Journal of Ethnopharmacology, 103, 25-35. https://doi.org/10.1016/j.jep.2005.09.024

[9] Hazni, H., Ahmad, N., Hitotsuyanagi, Y., Takeya, K. and Choo, C.Y. (2008) Phytochemical Constituents from Cassia alata with Inhibition against Methicillin-Resistant Staphylococcus aureus (MRSA). Planta Medica, 74, 1802-1805.

https://doi.org/10.1055/s-0028-1088340

[10] Scartezzini, P., Antognoni, F., Raggi, M.A., Poli, F. and Sabbioni, C. (2006) Vitamin C Content and Antioxidant Activity of the Fruit and of the Ayurvedic Preparation of Emblica officinalis Gaertn. Journal of Ethnopharmacology, 104, 113-118. https://doi.org/10.1016/j.jep.2005.08.065

[11] Parrotta, J.A. (2001) Healing Plants of Peninsular India. CABI Publishing, Wallingford, UK.

[12] Rege, N.N., Thatte, U.M. and Dahanukar, S.A. (1999) Adaptogenic Properties of Six Rasayana Herbs Used in Ayurvedic Medicine. Phytotherapy Research: PTR, 13, 275-291. https://doi.org/10.1002/(SICI)1099-1573(199906)13:4<275::AID-PTR510>3.0.CO;2-S

[13] Jeena, K.J., Joy, K.L. and Kuttan R. (1999) Effect of Emblica officinalis, Phyllanthus amarus and Picrorrhiza kurroa on N-Nitrosodiethylamine Induced Hepatocarcinogenesis. Cancer Letters, 136, 11-16. https://doi.org/10.1016/S0304-3835(98)00294-8

[14] Jose, J.K. and Kuttan, R. (2000) Hepatoprotective Activity of Emblica officinalis and Chyavanaprash. Journal of Ethnopharmacology, 72, 135-140. https://doi.org/10.1016/S0378-8741(00)00219-1

[15] Moure, A., Cruz, J.M., Franco, D., Domínguez, J.M., Sineiro, J., Domínguez, H., Núñez, M.J. and Parajó, J.C. (2001) Natural Antioxidants from Residual Sources. Food Chemistry, 72, 145-171. https://doi.org/10.1016/S0308-8146(00)00223-5

[16] Kim, J.S., Kuk, E., Yu, K.N., Kim, J.H., Park, S.J., Lee, H.J., Kim, S.H., Park, Y.K., Park, Y.H., Hwang, C.Y. and Kim, Y.K. (2007) Antimicrobial Effects of Silver Nanoparticles. Nanomedicine: Nanotechnology, Biology and Medicine, 3, 95-101. https://doi.org/10.1016/j.nano.2006.12.001

[17] Bhattacharya, S.K., Bhattacharya, D., Sairam, K. and Ghosal, S. (2002) Effect of Bioactive Tannoid Principles of Emblica officinalis on Ischemia-Reperfusion-Induced Oxidative Stress in Rat Heart. Phytomedicine, 9, 171-174. https://doi.org/10.1078/0944-7113-00090

[18] Perianayagam, J.B., Sharma, S.K., Joseph, A. and Christina, A.J. (2004) Evaluation of Anti-Pyretic and Analgesic Activity of Emblica officinalis Gaertn. Journal of Ethnopharmacology, 95, 83-85. 
[19] Manzocco, L., Anese, M. and Nicoli, M.C. (1998) Antioxidant Properties of Tea Extracts as Affected by Processing. LWT-Food Science and Technology, 31, 694-698. https://doi.org/10.1006/fstl.1998.0491

[20] Polash, S.A., Saha, T., Hossain, M.S. and Sarker, S.R. (2017) Investigation of the Phytochemicals, Antioxidant,and Antimicrobial Activity of the Andrographis paniculata Leaf and Stem Extracts. Advances in Bioscience and Biotechnology, 8, 149162. https://doi.org/10.4236/abb.2017.85012

[21] Deepa, N., Kaur, C., George, B., Singh, B. and Kapoor, H.C. (2007) Antioxidant Constituents in Some Sweet Pepper (Capsicum annuum L.) Genotypes during Maturity. LWT-Food Science and Technology, 40, 121-129. https://doi.org/10.1016/j.lwt.2005.09.016

[22] Yildirim, A., Mavi, A., Oktay, M., Kara, A.A., Algur, Ö.F. and Bilaloglu, V. (2000) Comparison of Antioxidant and Antimicrobial Activities of Tilia (Tiliaargentea Desf ex DC), Sage (Salvia triloba L.), and Black Tea (Camellia sinensis) Extracts. Journal of Agricultural and Food Chemistry, 48, 5030-5034. https://doi.org/10.1021/jf000590k

[23] Cook, N.C. and Samman, S. (1996) Flavonoids-Chemistry, Metabolism, Cardioprotective Effects, and Dietary Sources. The Journal of Nutritional Biochemistry, 7, 66-76. https://doi.org/10.1016/0955-2863(95)00168-9

[24] Irobi, O.N., Moo-Young, M., Anderson, W.A. and Daramola, S.O. (1994) Antimicrobial Activity of Bark Extracts of Bridelia ferruginea (Euphorbiaceae). Journal of Ethnopharmacology, 43, 185-190. https://doi.org/10.1016/0378-8741(94)90041-8

[25] Ekhaise, F.O. and Okoruwa, P. (2001) Antibacterial Activity of Aloe vera (Aloe barbadensis) Extract on Staphylococcus aureus. Tropical Journal of Environmental Science and Health, 4, 28-31.

Submit or recommend next manuscript to SCIRP and we will provide best service for you:

Accepting pre-submission inquiries through Email, Facebook, LinkedIn, Twitter, etc. A wide selection of journals (inclusive of 9 subjects, more than 200 journals) Providing 24-hour high-quality service User-friendly online submission system Fair and swift peer-review system Efficient typesetting and proofreading procedure Display of the result of downloads and visits, as well as the number of cited articles Maximum dissemination of your research work

Submit your manuscript at: http://papersubmission.scirp.org/

Or contact abb@scirp.org 